\author{
Inna Belfer · Beata Buzas · Heather Hipp \\ Gabriel Phillips · Julie Taubman · Ilona Lorincz \\ Catherine Evans · Robert H. Lipsky $\cdot$ Mary-Anne Enoch \\ Mitchell B. Max · David Goldman
}

\title{
Haplotype-based analysis of alpha 2A, 2B, and 2C adrenergic receptor genes captures information on common functional loci at each gene
}

Received: 17 August 2004/ Accepted: 7 October 2004/Published online: 8 December 2004

(C) The Japan Society of Human Genetics and Springer-Verlag 2004

\begin{abstract}
The alpha 2-adrenergic receptors $\left(\alpha_{2}\right.$-AR) mediate physiological effects of epinephrine and norepinephrine. Three genes encode $\alpha_{2}$-AR subtypes carrying common functional polymorphisms (ADRA2A Asn251Lys, ADRA2B Ins/Del301-303 and ADRA2C Ins/Del322-325). We genotyped these functional markers plus a panel of single nucleotide polymorphisms evenly spaced over the gene regions to identify gene haplotype block structure. A total of 24 markers were genotyped in 96 Caucasians and 96 African Americans. $A D R A 2 A$ and $A D R A 2 B$ each had a single haplotype block at least 11 and $16 \mathrm{~kb}$ in size, respectively, in both populations. $A D R A 2 C$ had one haplotype block of $10 \mathrm{~kb}$ in Caucasians only. For the three genes, haplotype diversity and the number of common haplotypes were highest in African Americans, but a similar number of
\end{abstract}

Supported by National Institutes of Health (NIH) Intramural Grants Z01 DE00366 and Z01 AA000301 and the Comprehensive Neuroscience Program Grant USUHS G192BR-C4 (Henry Jackson Foundation)

I. Belfer · B. Buzas · H. Hipp · G. Phillips

I. Lorincz $\cdot$ C. Evans $\cdot$ M. B. Max

Pain and Neurosensory Mechanisms Branch,

National Institute of Dental and Craniofacial Research,

Bethesda, 20892, MD, USA

I. Belfer $\cdot$ B. Buzas $\cdot$ H. Hipp $\cdot$ G. Phillips $\cdot$ J. Taubman

I. Lorincz · C. Evans · R. H. Lipsky · M.-A. Enoch · D. Goldman Laboratory of Neurogenetics,

National Institute on Alcohol Abuse and Alcoholism, Department of Health and Human Services,

National Institutes of Health,

Bethesda, 20892, MD, USA

I. Belfer $(\square)$

National Institutes of Health,

12420 Parklawn Drive, Suite 451, MSC 8110,

Rockville, MD 20852, USA

E-mail: ibelfer@mail.nih.gov

Tel.: + 1-301-4028323

Fax: + 1-301-4438579 markers (3-6) per block was sufficient to capture maximum diversity in either population. For each of the three genes, the haplotype was capable of capturing the information content of the known functional locus even when that locus was not genotyped. The $\alpha_{2}$-AR haplotype maps and marker panels are useful tools for genetic linkage studies to detect effects of known and unknown $\alpha_{2}$-AR functional loci.

Keywords Single-nucleotide polymorphism - Insertion/ deletion polymorphism - Linkage disequilibrium . Haplotype - Alpha 2-adrenergic receptors $A D R A 2 A$. $A D R A 2 B \cdot A D R A 2 C$

\section{Introduction}

Alpha 2-adrenergic receptors $\left(\alpha_{2}-\mathrm{AR}\right)$ are widely distributed in the human central and peripheral nervous systems. They are cell surface G-protein-coupled receptors for the endogenous catecholamines, epinephrine and norepinephrine, mediating part of the diverse biological effects of these neurotransmitters. They are involved in the regulation of blood pressure by mediating contraction of vascular smooth muscle and induction of coronary vasoconstriction in humans (Civantos Calzada and Aleixandre de Artinano 2001; Comings et al. 2000). These receptors also modulate sedation, analgesia, insulin release, renal function, cognition, memory, and behavior (Berthelsen and Pettinger 1977; McGrath et al. 1989; Timmermans and van Zwieten 1981). Three distinct subtypes of $\alpha_{2}-\mathrm{AR}-\alpha 2 \mathrm{~A}, \alpha 2 \mathrm{~B}$, and $\alpha 2 \mathrm{C}$-have been identified in multiple mammalian species by molecular and pharmacological research. Because of the lack of subtype-selective agonists and antagonists, mice overexpressing, totally lacking (knockout), or expressing heavily modified $\alpha_{2}$-AR subtypes have been generated to determine the specific functions of the three $\alpha_{2}$-AR 
subtypes (MacDonald et al. 1997). Each of the $\alpha_{2}$-AR subtypes is specific in its distribution in tissues and cells, ontogenetic pattern, regulation, and physiological functions (Shishkina and Dygalo 2002).

Alpha $2 \mathrm{~A}$ receptors are the predominant $\alpha_{2}$-AR subtype in the central nervous system where they modulate sympathetic outflow and mediate the central antihypertensive action of the $\alpha_{2}$-AR agonists clonidine and moxonidine (Gavras et al. 2001). The $\alpha 2 \mathrm{~B}$ subtype is the principal mediator of the hypertensive response to $\alpha_{2}$-AR agonists, appears to play a role in salt-induced hypertension by eliciting a sympathoexcitatory response, and may be important in developmental processes (Kintsurashvili et al. 2003). The $\alpha 2 \mathrm{C}$ subtype is involved in many central nervous system processes including the startle reflex, stress response, and locomotion. Both $\alpha 2 \mathrm{~A}$ and $\alpha 2 \mathrm{C}$ are essential, as deletion of $\alpha 2 \mathrm{~A}$ and $\alpha 2 \mathrm{C}$ receptors leads to cardiac hypertrophy and failure due to chronically enhanced catecholamine release (Hein 2001).

Physiologic functions controlled by different $\alpha_{2}$-AR subtypes, including cardiovascular and other responses to $\alpha_{2}$-AR agonists, are subject to interindividual variation in the human population. It can be speculated that some of the interindividual variation in responses is explained by genetic variation in the receptors producing changes in the amount or structure of the receptors. In support of a role for genetic variation, several physiologic parameters modulated by adrenergic function are heritable, e.g., blood pressure (Mathias et al. 2003), nociception (Lariviere et al. 2002), mood, and anxiety (Johansson et al. 2001).

Each $\alpha_{2}$-AR subtype is encoded by a unique gene. Three genes (ADRA2A: hCG41806, ADRA2B: hCG37297, and $A D R A 2 C$ : hCG1981539) are located on chromosomes 10q24-q26, 2p13-q13, and 4 p16 respectively. They are all intronless and approximately $2.8-3.7 \mathrm{~kb}$ in length. For each $\alpha_{2}$-AR subtype, sequence variations within the coding region of each gene that alter the structure of each $\alpha_{2}$-AR protein have been identified in humans. These result in substitutions or deletions of amino acids in the third intracellular loops of each receptor. The consequences of each polymorphism for receptor signaling, as determined in transfected cells, include alterations in G-protein coupling, desensitization, and G-proteinreceptor kinase-mediated phosphorylation (Small and Liggett 2001). The prevalences of the polymorphisms differ across ethnic populations. The three polymorphisms are each relatively abundant, and two are functional in vitro.

$A D R A 2 A$ Asn251Lys is a functional amino acid substitution. Lys 251 confers significantly increased agonist-promoted binding to $\mathrm{Gi}$, leading to greater inhibition of adenylyl cyclase, activation of MAP kinase signaling, and stimulation of inositol phosphate accumulation (Small et al. 2000a). Lys 251 has a frequency of 0.05 in African Americans compared with 0.004 in Caucasians, but is not associated with essential hypertension.
A polymorphism of $A D R A 2 B$ consisting of a deletion of three glutamic acids (residues 301-303) from a glutamic acid repeat element in the third intracellular loop is more common in Caucasians (allele frequency 0.31) than African Americans (allele frequency 0.12) (Small et al. 2001). The presence of the del 301-303 allele leads to a small decrease in coupling efficiency resulting in reduced inhibition of adenylyl cyclase (Makaritsis et al. 1999). It has been associated with a reduced basal metabolic rate in obese subjects, with an increase in body weight among nondiabetic subjects, and modulation of autonomic nervous function in nondiabetic men (Sivenius et al. 2001, 2003). However, there is no evidence on the role of this $A D R A 2 B$ variant in genetic susceptibility to essential hypertension mediated by $A D R A 2 B$.

In $A D R A 2 C$, six sequence variants include five synonymous substitutions (allele frequencies 0.006-0.25) and an in-frame 12-nucleic acid deletion encoding a receptor lacking Gly-Ala-Gly-Pro in the third intracellular loop at codons 322-325 (Feng et al. 2001; Small et al. 2000b). This deletion allele has frequencies of approximately 0.44 in African Americans and 0.035 in Caucasians (Feng et al. 2001). There is in vitro evidence that the deletion alters high-affinity agonist binding, indicating impaired formation of the agonist-receptorG-protein complex (Small et al. 2000b). Since studies with $\alpha 2 \mathrm{C}$ knockout mice and mice overexpressing $\alpha 2 \mathrm{C}$ revealed changes in behavior and catecholaminergic function, such as locomotor activity in response to amphetamine, isolation-induced aggression paradigm or levels of dopamine, norepinephrine and serotonin (Kable et al. 2000), this functional variant may also be associated with effects on the same phenotypes in humans.

Each of the $\alpha_{2}$-AR genes displays a functional polymorphism, but the currently known variants only contribute modestly to gene expression and/or function. Other functional loci may be present, including polymorphisms that are known but have not yet been recognized to be functional. Therefore, we have combined two genetic approaches - study of individual functional variants and haplotype analysis - to provide comprehensive coverage of the candidate gene for information content. In the present study, we develop a haplotype map for each of the three $\alpha_{2}$-AR for two populations, American Caucasians and African Americans, by genotyping a panel of SNP markers and the known functional polymorphisms in these populations.

\section{Materials and methods}

\section{Participants}

A total of 192 unrelated subjects were genotyped, including 96 individuals from each of two populations: U.S. Caucasians and African Americans. Informed consent was obtained according to human research protocols approved by the human research committees 
of the recruiting institutes: the National Institute on Alcohol Abuse and Alcoholism, National Institute of Mental Health, and Rutgers University. All participants had been psychiatrically interviewed, and none had been diagnosed with a psychiatric disorder.

\section{SNP markers}

The physical position and frequency of minor alleles $(>0.05)$ from a commercial database (Celera Discovery System, CDS, November 2003) were used to select SNPs. $5^{\prime}$ nuclease assays (vide infra) could be designed for nine $A D R A 2 A$, eight $A D R A 2 B$, and seven $A D R A 2 C$ SNPs and could be genotyped in highly accurate fashion. These panels of approximately equally spaced markers covered the entire genes plus 4-6 kb upstream and 4-6 kb downstream each gene.

\section{Genomic DNA}

Genomic DNA was extracted from lymphoblastoid cell lines and diluted to a concentration of $10 \mathrm{ng} / \mu \mathrm{l}$. Aliquots of $1 \mu \mathrm{l}$ aliquots were dried in 384-well plates. Genotyping was performed by the $5^{\prime}$ nuclease method (Shi et al. 1999) using fluorogenic allele-specific probes. Oligonucleotide primer and probe sets were designed based on gene sequence from the CDS, November 2003. Primers and detection probes for each locus in each gene are listed in Table 1.

Reactions were in a $5-\mu 1$ volume containing $2.375 \mu \mathrm{l}$ TE, $2.5 \mu \mathrm{l}$ Master Mix (ABI, Foster City, CA, USA) with AmpliTaq gold DNA polymerase, dNTPs, gold buffer and $\mathrm{MgCl}_{2}$ 10-ng genomic DNA, $900 \mathrm{nM}$ of each forward and reverse primer, and $100 \mathrm{nM}$ of each reporter and quencher probe. DNA was incubated at $50^{\circ} \mathrm{C}$ for $2 \mathrm{~min}$ and at $95^{\circ} \mathrm{C}$ for $10 \mathrm{~min}$ and amplified on an ABI 9700 device for 40 cycles at $95^{\circ} \mathrm{C}$ for $30 \mathrm{~s}$ and $60^{\circ} \mathrm{C}$ for $75 \mathrm{~s}$. Allele-specific signals were distinguished by measuring endpoint 6-FAM or VIC fluorescence intensities at $508 \mathrm{~nm}$ and $560 \mathrm{~nm}$, respectively, and genotypes were generated using Sequence Detection V.1.7 (ABI). Genotyping error rate was directly determined by regenotyping $25 \%$ of the samples, randomly chosen, for each locus. The overall error rate was $<0.005$. Genotype completion rate was 0.99 .

\section{Non-SNP markers}

Two known functional deletion polymorphisms in $A D R A 2 B$ and $A D R A 2 C$ were genotyped by DNA fragment analysis on a capillary sequencer (ABI 3100). Forward and reverse primers were designed using Vector NTI Software (InforMax Inc., Bethesda, MD, USA); their sequences are shown in Table 1. To amplify DNA fragments, optimization was performed at varying annealing temperatures and magnesium chloride concentrations. The $A D R A 2 B$ ins/del $20 \mu$ reaction volume contained $100 \mathrm{ng}$ genomic DNA, $2 \mu \mathrm{l} 10 \times$ Buffer II (ABI), $1.5 \mathrm{mM} \mathrm{MgCl}, 20 \mathrm{ng}$ of each primer, $0.2 \mathrm{mM}$ dNTPs (Invitrogen), and $1 \mathrm{U}$ Taq Gold Polymerase (ABI). The $A D R A 2 C$ ins/del $20-\mu \mathrm{l}$ reaction volume also contained $100 \mathrm{ng}$ genomic DNA and $20 \mathrm{ng}$ of each primer but $4 \mu \mathrm{l} 5 \times$ buffer A (Invitrogen), $0.8 \mathrm{mM}$ dNTPs (ABI), $0.5 \mu$ Platinum Taq Polymerase (Invitrogen), and $2 \mu \mathrm{l}$ DMSO. ADRA2B ins/del was amplified by a 12 -min hot start at $95^{\circ} \mathrm{C}$ followed by 40 cycles of $30 \mathrm{~s}$ at $95^{\circ} \mathrm{C}, 30 \mathrm{~s}$ at the optimal annealing temperature $\left(65^{\circ} \mathrm{C}\right)$, $30 \mathrm{~s}$ at $72^{\circ} \mathrm{C}$ for elongation, and a final $10 \mathrm{~min}$ elongation at $72^{\circ} \mathrm{C}$. $A D R A 2 C$ ins/del was amplified by a 4-min hot start at $94^{\circ} \mathrm{C}$ followed by 35 cycles of $30 \mathrm{~s}$ at $94^{\circ} \mathrm{C}$, $30 \mathrm{~s}$ at the optimal annealing temperature $\left(65^{\circ} \mathrm{C}\right), 30 \mathrm{~s}$ at $72^{\circ} \mathrm{C}$ for elongation, and a final 7 -min elongation at $72^{\circ} \mathrm{C}$. PCR was carried out with an ABI 9700. ADRA2B and $A D R A 2 C$ amplicons were mixed together and with $3 \mu \mathrm{l}$ of internal standard ROX 500 (ABI) and denatured at $95^{\circ} \mathrm{C}$ for $5 \mathrm{~min}$. Data collected by ABI 3100 Genetic Analyzer were further analyzed by Genotyper V. 1.0.1 on the device.

\section{Haplotype analysis}

Haplotype frequencies were estimated using a Bayesian approach implemented with PHASE (Stephens et al. 2001). These frequencies closely agreed with results from a maximum likelihood method implemented via an expectation-maximization (EM) algorithm (Long et al. 1995). Haploview V. 2.0.2 (Whitehead Institute for Biomedical Research, USA) was used to produce LD matrices. Haplotype blocks were reconstructed using the pairs of markers with LD greater than 0.85 (Gabriel et al. 2002). SNPTagger (Ke and Cardon 2003) was used to determine the minimum SNP set that provides maximal haplotype diversity. Tag SNPs were identified by running the "Fraction of haplotype patterns to be covered," being 0.85 , using all the haplotypes produced by PHASE. The SNP sets we indicate is one possible alternative from among several that may be closely equivalent.

\section{Results and discussion}

Of a total of 24 markers in three $\alpha_{2}$-AR genes, 23 were polymorphic both in Caucasians and African Americans. The functional ADRA2A SNP Asn251Lys was monomorphic in Caucasians. Dramatic interpopulation differences in allele frequencies were observed for most of the markers. Allele frequencies of all markers and their locations in the genes are shown in Table 2. The majority of the markers are located in the intergenic space upstream and downstream of each gene (Fig. 1 ac). Functional nonsynonymous and one synonymous substitutions are located in the $A D R A 2 A$ exon, and one marker is located in its $3^{\prime}$ UTR region. A functional 
Table 1 Primer and probe sequences for $5^{\prime}$ nuclease genotyping

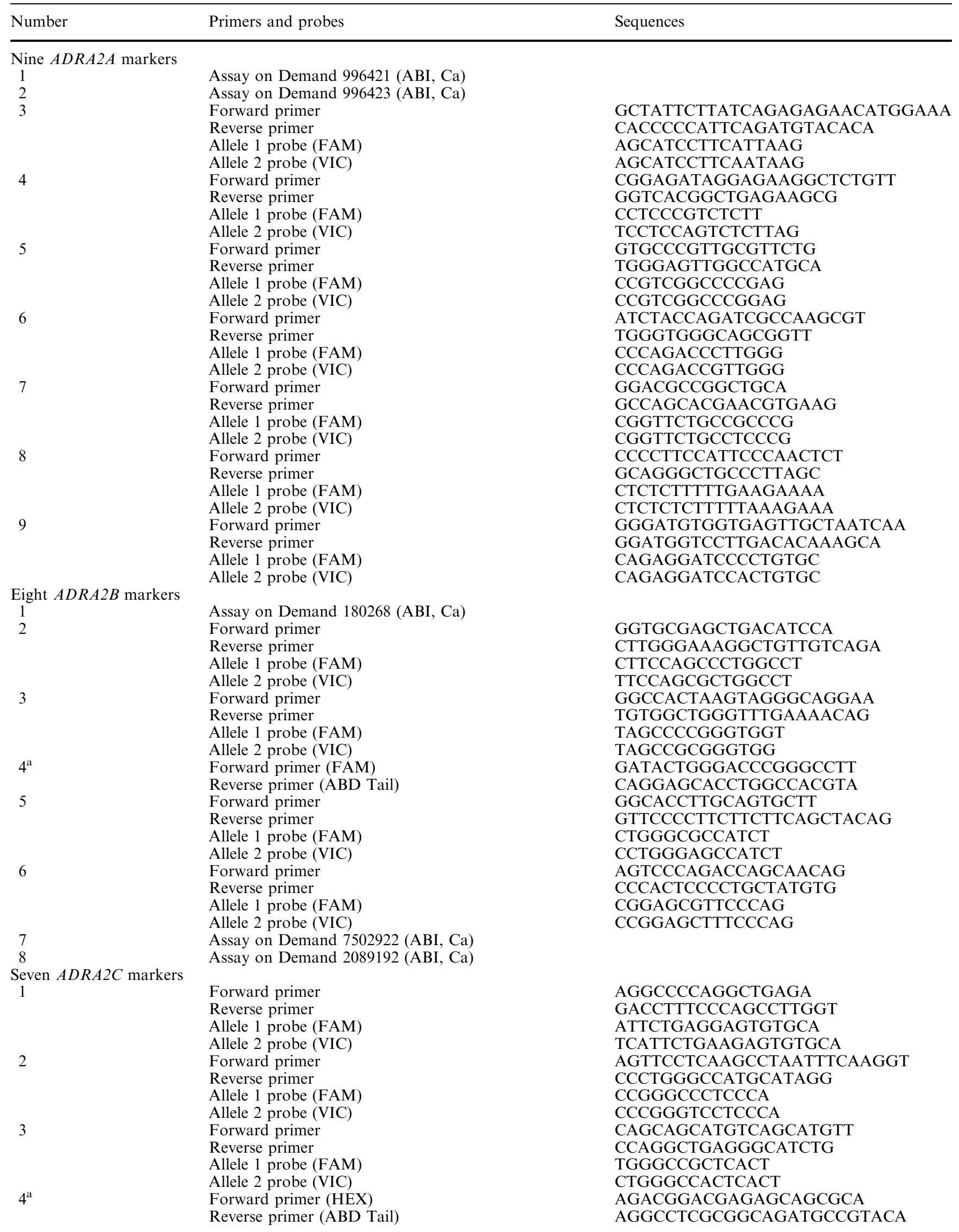


Table 1 (Continued)

\begin{tabular}{lll}
\hline Number & Primers and probes & Sequences \\
\hline 5 & Forward primer & TGCAGCCCTGCCTTTCC \\
& Reverse primer & AGCAGCAGTGTGAACAGTGT \\
& Allele 1 probe (FAM) & CACCGTCAGGCCCA \\
& Allele 2 probe (VIC) & CACCGTGAGGCCCA \\
6 & Forward Primer & GTCAAGGCCGATGAGGACAT \\
& Reverse Primer & AGCTGGGCCAACAGTTCAG \\
7 & Allele 1 probe (FAM) & CCTCCCCCGACCAGA \\
& Allele 2 probe (VIC) & CCTCCCCCAACCAGA \\
& Forward Primer & ATGGGACTCAGAGAGGTGGATT \\
& Reverse Primer & GGGTCTTATCACCAGCTGTGT \\
& Allele 1 probe (FAM) & AACCTGCCTGAGGTC \\
\hline
\end{tabular}

${ }^{a}$ Marker 4 is insertion/deletion (assay with labeled primers)

Table 2 Locations and allelic frequencies. Physical locations are from the Celera Discovery System (CDS) database, November 2003. NCBI IDs are from the National Center for Biotechnology Information database, November 2003

\begin{tabular}{|c|c|c|c|c|c|c|c|}
\hline Number & SNP ID (CDS) & SNP ID (NCBI) & Variation & Position (CDS) & Location & \multicolumn{2}{|c|}{ Allelic frequency (for allele 2) } \\
\hline $1^{\mathrm{a}, \mathrm{b}}$ & hCV996421 & rs638019 & $\mathrm{G}>\mathrm{A}$ & 106563427 & $5^{\prime}$ Intergenic & .26 & .83 \\
\hline $2^{\mathrm{b}}$ & hCV996423 & rs491589 & $\mathrm{T}>\mathrm{C}$ & 106566230 & $5^{\prime}$ Intergenic & .86 & .77 \\
\hline $3^{\mathrm{b}}$ & hCV3181570 & rs521674 & $\mathrm{T}>\mathrm{A}$ & 106567188 & $5^{\prime}$ Intergenic & .28 & .76 \\
\hline $4^{\mathrm{b}}$ & hCV7611986 & rs 1800763 & $\mathrm{C}>\mathrm{A}$ & 106567590 & $5^{\prime}$ Intergenic & .03 & .21 \\
\hline $7^{\mathrm{b}}$ & hCV27473723 & rs 1800038 & $\operatorname{Arg} 365 \operatorname{Arg}(G>T)$ & 106570940 & Exon 1 & .01 & .08 \\
\hline 8 & hCV996424 & rs553668 & $\mathrm{G}>\mathrm{A}$ & 106571177 & UTR 3' & .17 & .31 \\
\hline 9 & hCV3181571 & rs602618 & $\mathrm{C}>\mathrm{A}$ & 106574687 & $3^{\prime}$ Intergenic & .72 & .32 \\
\hline \multicolumn{8}{|c|}{ Eight $A D R A 2 B$ markers in 96 individuals from each of two populations } \\
\hline $1^{\mathrm{a}}$ & hCV180268 & rs13019188 & $\mathrm{G}>\mathrm{A}$ & 91215007 & $3^{\prime}$ Intergenic & .44 & .31 \\
\hline $2^{\mathrm{b}}$ & hCV11510924 & rs7561198 & $\mathrm{C}>\mathrm{G}$ & 91215789 & $3^{\prime}$ Intergenic & .63 & .77 \\
\hline 8 & hCV2089192 & rs893173 & $\mathrm{T}>\mathrm{C}$ & 91230594 & $5^{\prime}$ Intergenic & .43 & .31 \\
\hline \multicolumn{8}{|c|}{ Seven $A D R A 2 C$ markers in 96 individuals from each of two populations } \\
\hline $1 \&$ & hCV179118 & rs 7692883 & $\mathrm{G}>\mathrm{A}$ & 3665266 & $5^{\prime}$ Intergenic & .12 & .27 \\
\hline $2 \&$ & hCV7667800 & rs7667600 & $\mathrm{C}>\mathrm{T}$ & 3668271 & $5^{\prime}$ Intergenic & .67 & .33 \\
\hline $3 \&$ & hCV179119 & rs9790376 & $\mathrm{G}>\mathrm{A}$ & 3668479 & $5^{\prime}$ Intergenic & .71 & .39 \\
\hline $4^{\mathrm{e}} \&$ & ADRA2C Ins/ Del & No rs & Del $>$ nondel & $3672440-3672451$ & Exon & .94 & .58 \\
\hline $5 \&$ & hCV7666697 & rs7678463 & $\mathrm{C}>\mathrm{G}$ & 3673796 & $3^{\prime}$ Intergenic & .86 & .42 \\
\hline $6 \&$ & hCV7666695 & rs13109333 & $\mathrm{G}>\mathrm{A}$ & 3674571 & $3^{\prime}$ Intergenic & .83 & .56 \\
\hline 7 & hCV499376 & rs13112010 & $\mathrm{C}>\mathrm{G}$ & 3675087 & $3^{\prime}$ Intergenic & .55 & .20 \\
\hline
\end{tabular}

${ }^{a}$ Indicates tag SNPs for Caucasians

${ }^{b}$ Indicates tag SNPs for African Americans

${ }^{c}$ Marker 6 is a known functional polymorphism

insertion/deletion polymorphism and one synonymous substitution are located in the $A D R A 2 B$ exon. In $A D R A 2 C$, the functional insertion/deletion polymorphism is located in the coding region (exon). All genotype frequencies conformed to Hardy-Weinberg equilibrium.

Within the $A D R A 2 A$ and $A D R A 2 B$ regions, a single conserved haplotype block 11 and $16 \mathrm{~kb}$ in size, respectively, spanned each gene in both populations (Fig. 2 a,b) and the block boundaries extend beyond the
${ }^{d}$ Marker 4 is a known functional polymorphism

${ }^{e}$ Marker 4 is a known functional polymorphism

region we have evaluated. The $A D R A 2 C$ region had one haplotype block of $10 \mathrm{~kb}$ in Caucasians. In African Americans, no haplotype block was identified since only the first and last SNPs were in strong linkage disequilibrium (LD) with all other markers (Fig. 2 c). One possible reason for this could be excessive recombination in this population that might happen particularly because of the physical location of $A D R A 2 C$ at the very top of chromosome 4. Isolated nucleotide substitutions occurring within nonrecombined blocks can also 
Fig. 1a-c Location of singlenucleotide polymorphisms genotyped in $A D R A 2 A$, $A D R A 2 B$, and $A D R A 2 C$. Coding exons are shown as solid blocks. Physical locations are from the Celera Discovery System (CDS) database, November 2003. $A D R 2 B$ is transcribed in reverse orientation
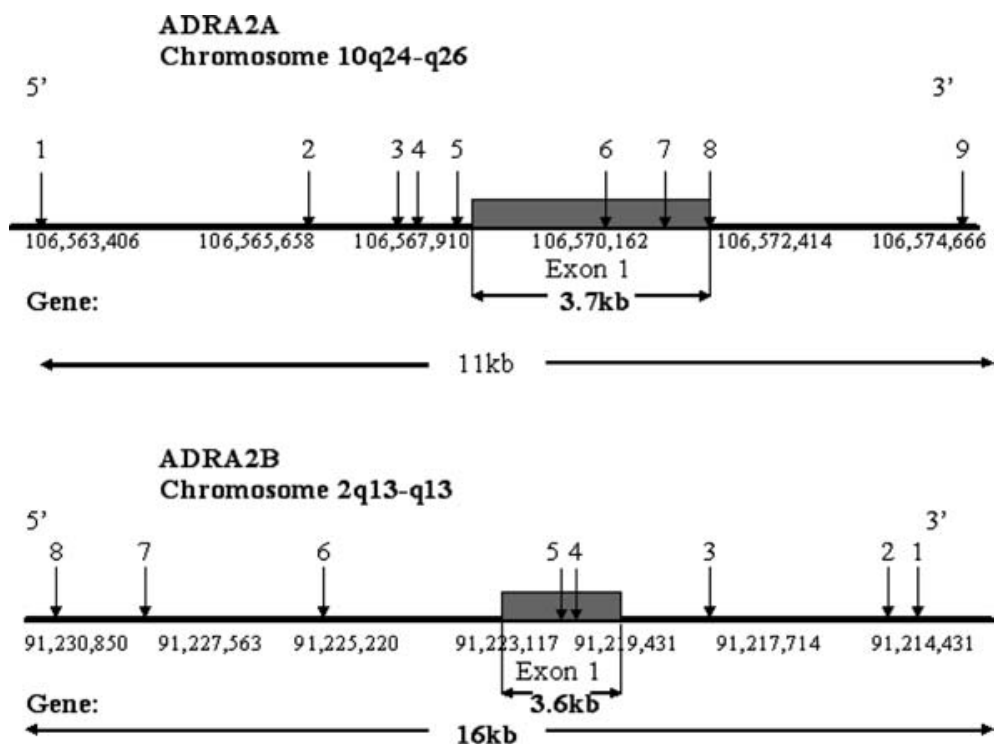

ADRA2C

Chromosome 4p16

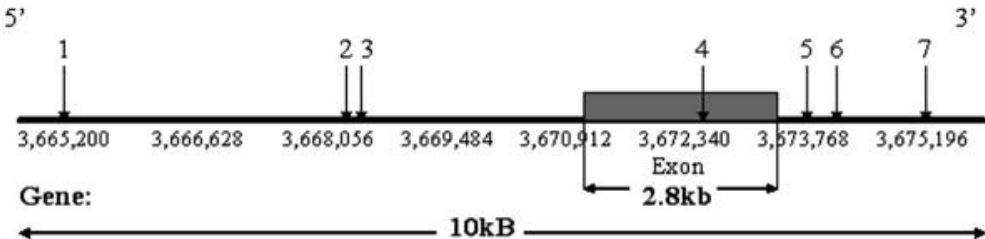

contribute to the lack of LD in the region. Finally, recent studies reveal only a partial fit to the fundamentally "block-like" structure of the human genome (Wall and Pritchard 2003a, 2003b), and some regions including $A D R A 2 C$ may not conform this model. Since the $A D R A 2 C$ panel was of high marker density (seven markers across $10 \mathrm{~kb}$ involving $2.8 \mathrm{~kb}$ of the actual gene sequence), no improvement in the definition of haplotype block structure could be expected by expanding the population size (Wall and Pritchard 2003a).

Definition of haplotype blocks and block boundaries is inexact. Some disruptions of LD occurring within blocks are attributable to low allele frequencies that lead to increased variance in estimation of LD. We discounted low $\mathrm{D}^{\prime}$ values that might have originated from this cause. In the $A D R A 2 A, A D R A 2 B$, and $A D R A 2 C$ haplotype block regions, D' was generally $>0.85$ from one end of the region to the other. Average D' values within haplotype blocks in Caucasians and Africa -Americans were, respectively, $A D R A 2 A: 0.97$ and 0.91, ADRA2B: 1.00 and 0.99, and $A D R A 2 C$ : 0.83 and 0.56 . Median $\mathrm{D}^{\prime}$ values within the haplotype blocks from both Caucasians and African Americans were high: $A D R A 2 A: 1.00$ and 1.00, $A D R A 2 B: 1.00$ and 1.00 , and $A D R A 2 C: 0.88$ and 0.57 , indicating that most pairs of loci within these regions are in very high LD.

Haplotype frequencies for $A D R A 2 A$ and $A D R A 2 B$ in both populations are shown in Table 3. For each population and haplotype block, two to seven common (frequency $\geq 0.05$ ) haplotypes accounted for most of the total: $78-95 \%$ of Caucasian and $73-89 \%$ of African American haplotypes. For Caucasians and African Americans, the numbers of common (frequency $\geq 0.05$ ) haplotypes were in $A D R A 2 A, 3$ and 7; in $A D R A 2 B, 2$ and 2; and in $A D R A 2 C, 4$ and 8, respectively.

An important aspect of understanding the level of genetic information content within and between haplotype blocks is haplotype diversity (informativeness). For each $\alpha_{2}$-AR gene haplotype block, a panel of markers sufficient to maximize genetic information content was available to address this issue. We evaluated haplotype diversity within each block by successively subtracting SNPs to the haplotypes to evaluate the increment/decrement in diversity contributed by each SNP. SNPs were serially subtracted in that order that minimized the decrement in diversity at each step and until only a single SNP (i.e., the SNP with the highest heterozygosity) remained. The chosen measure of diversity (haplotype frequencies and diplotype heterozygosity) was recalculated for each SNP panel size $(n, n-1 \ldots 1)$. At some point for each haplotype block and for each population, adding or subtracting an SNP does not appreciably alter diversity, as shown in Fig. 3 a-c. For $A D R A 2 A$ and $A D R A 2 C$, haplotype diversity was highest in African Americans. A similar number of markers (three to five) was necessary to capture maximum diversity in either population (with the exception of the $A D R A 2 A$ 

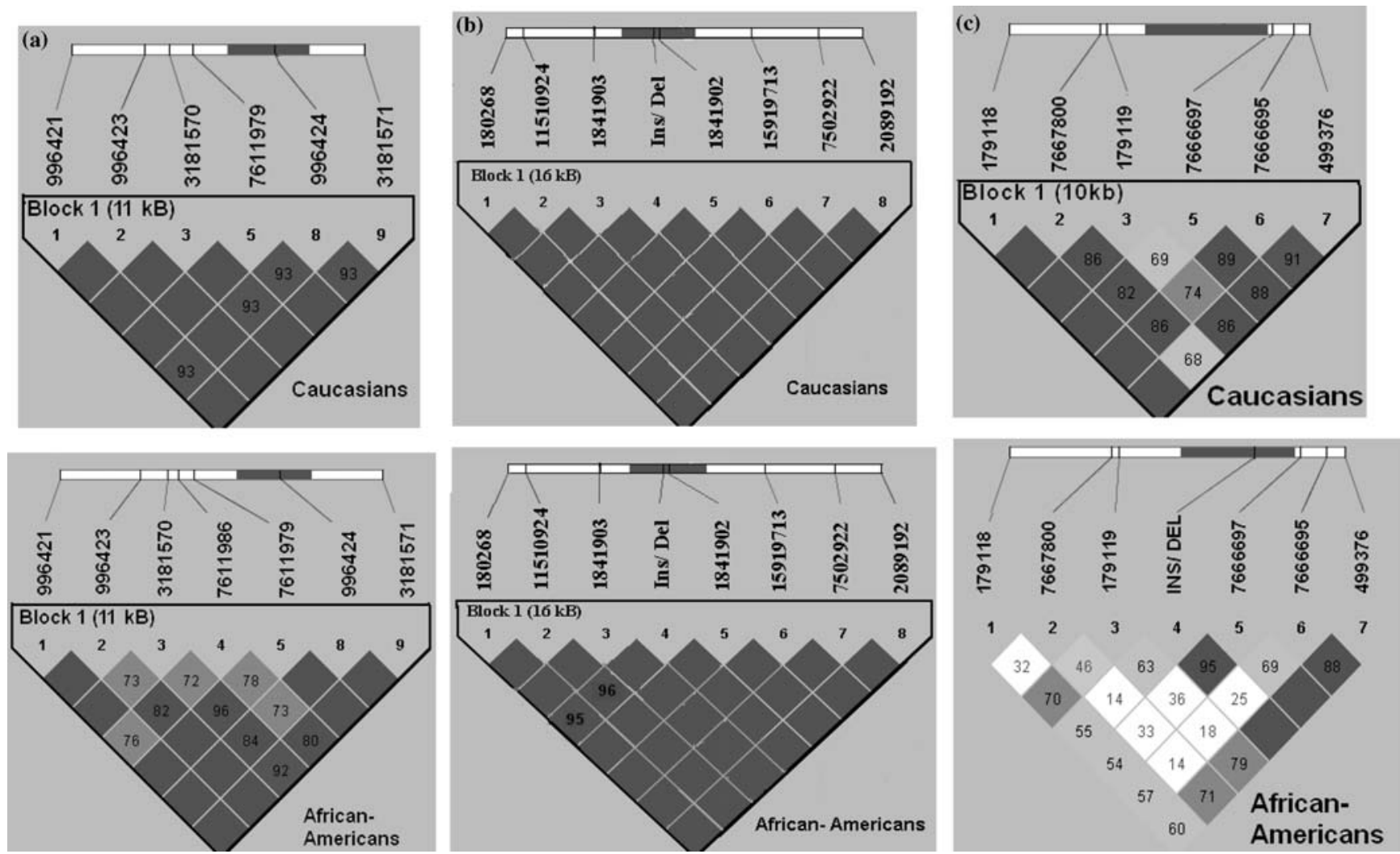

Fig. 2a-c Haplotype block organization of $A D R A 2 A, A D R A 2 B$, and $A D R A 2 C$. Each box represents percent of linkage disequilibrium (LD) ( $D^{\prime}$ ) between pairs of markers, as generated by Haploview (Whitehead Institute for Biomedical Research, USA). $D^{\prime}$ is color coded, the black box indicating complete (1.00) $D$ ' between locus pairs. $A D R A 2 A$ and $A D R A 2 C$ LD matrices were estimated without low frequency markers

haplotype block, which required six markers to capture maximum diversity). This number represents an optimal panel, itself derived from the larger panel of SNP markers we genotyped. The SNPs that constitute the minimal set necessary to maximize haplotype diversity (85\% of haplotypes covered) are indicated in Table 2.

For each $\alpha_{2}$-AR gene, a known functional polymorphism was contained within the haplotype block. Within each block, haplotypes enabled high sensitivity of detection of the functional locus (when a functional allele was present, the particular haplotype(s) was present) and specificity of detection (when the haplotype(s) was present the functional allele was present). For each of the three $\alpha_{2}$-AR genes, the haplotype was capable of capturing all or almost all the information provided by directly genotyping the functional locus in either population (Table 4). These SNP panels covering $\alpha_{2}$-AR gene regions reliably capture haplotype diversity in different populations even when not including known functional alleles. Certainly, genotyping of polymorphisms that affect gene expression and/or function is highly important in association/linkage studies. However, there is a possibility that an unrecognized functional locus contributes to a phenotype. The focus of the haplotype-
Table 3 Frequencies of haplotypes

Number Common haplotypes Frequencies

Caucasians African Americans

In $A D R A 2 A$ constructed from nine markers $(1=$ allele 1 ; $2=$ allele 2 )

$\begin{array}{llll}1 & 121112112 & 0.72 & 0.16 \\ 2 & 212122121 & 0.15 & 0.21 \\ 3 & 222122111 & 0.08 & 0.18 \\ 4 & 22222111 & 0.03 & 0.17 \\ 5 & 222122221 & 0.00 & 0.07 \\ 6 & 222112112 & 0.00 & 0.05 \\ 7 & 221112112 & 0.00 & 0.05 \\ 8 & 222111112 & 0.00 & 0.03\end{array}$

In $A D R A 2 B$ constructed from eight markers $(1=$ allele 1 ;

$\begin{array}{llll}2=\text { allele } 2) & & \\ 1 & 12221111 & 0.56 & 0.67 \\ 2 & 21112222 & 0.39 & 0.22 \\ 3 & 22121112 & 0.03 & 0.03\end{array}$

In $A D R A 2 C$ constructed from seven markers $(1=$ allele 1 ; $2=$ allele 2)

\begin{tabular}{llll}
$2=$ allele 2$)$ & & \\
1 & 1222222 & 0.49 & 0.15 \\
2 & 1112221 & 0.11 & 0.13 \\
3 & 2222221 & 0.10 & 0.02 \\
4 & 1112111 & 0.08 & 0.07 \\
5 & 1211111 & 0.02 & 0.07 \\
6 & 1121111 & 0.03 & 0.06 \\
7 & 1111111 & 0.01 & 0.05 \\
8 & 2111121 & 0.00 & 0.14 \\
9 & 1122111 & 0.00 & 0.06 \\
\hline
\end{tabular}

based approach to analyzing case-control populations has been to detect the effects of every functional locus, known or unknown. 

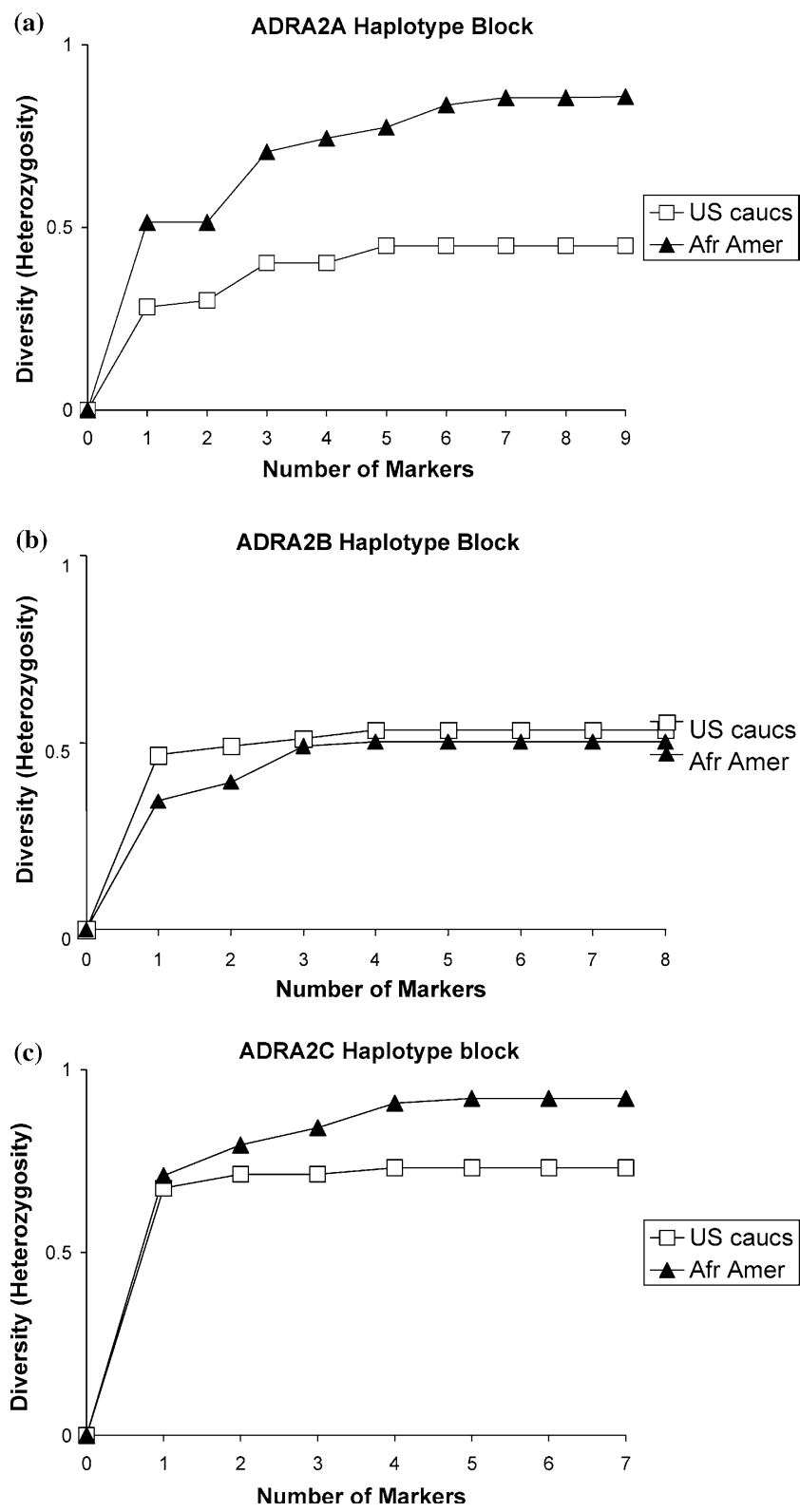

Fig. 3a-c Effect of successive subtraction/addition of SNPs on $\alpha$ AR haplotype diversity in two populations. SNPs were successively subtracted from haplotypes in such a way as to minimize loss of diversity (diplotype heterozygosity, $Y$ axis]. For each block, marker panels are sufficient to maximize diversity, and diversity can be generally maximized with three to five optimal markers. For each haplotype panel, addition of the functional $\alpha$-AR locus yields no further increment in diversity

Some functional polymorphisms have low frequencies in certain populations. For example, ADRA2A Asn251Lys is relatively common in African Americans (allele frequency 0.05 ) but only has a frequency of 0.004 in Caucasians, making it uninformative in studies limited to a small number of individuals. The $A D R A 2 A$ SNP panel developed here includes eight markers in addition to Asn251Lys. When Asn251Lys is excluded, there is essentially no loss of $A D R A 2 A$ information content in either African Americans or Caucasians (Table 4).
Table 4 Effect of functional marker on haplotype diversity

\begin{tabular}{llll}
\hline Variation & $\begin{array}{l}\text { Marker } \\
\text { frequency }\end{array}$ & $\begin{array}{l}\text { Haplotype } \\
\text { diversity } \\
\text { with marker }\end{array}$ & $\begin{array}{l}\text { Haplotype } \\
\text { diversity } \\
\text { without } \\
\text { marker }\end{array}$ \\
\hline In Caucasians & & & \\
ADRA2A (Asn 251) & 0.00 & 0.46 & 0.46 \\
ADRA2B Del & 0.37 & 0.53 & 0.53 \\
ADRA2C Del & 0.06 & 0.73 & 0.73 \\
In African Americans & & & \\
ADRA2A (Asn 251) & 0.03 & 0.853 & 0.851 \\
ADRA2B Del & 0.21 & 0.51 & 0.51 \\
ADRA2C Del & 0.42 & 0.92 & 0.91 \\
\hline
\end{tabular}

For the $\alpha_{2}$-AR genes, we created multilocus SNP panels to define a specific LD structure across each gene region. Each panel is sufficient to capture the signal of the moderately abundant known functional locus at each gene, and these panels should also be informative for unknown functional loci. By using a comprehensive haplotype-based approach for the development of $\alpha_{2}$-AR gene haplotype maps and marker panels, our study provides the basis for future studies to investigate the role of genetic risk factors associated with known and unknown functional loci in pathophysiological conditions linked to alpha 2-adrenergic receptor function.

Acknowledgements We are grateful to Dr. Alec Roy for a subset of his population dataset and to Longina Akhtar for assistance with cell culture.

\section{References}

Berthelsen S, Pettinger WA (1977) A functional basis for classification of alpha-adrenergic receptors. Life Sci 21:595-606

Civantos Calzada B, Aleixandre de Artinano A (2001) Alphaadrenoceptor subtypes. Pharmacol Res 44:195-208

Comings DE, Johnson JP, Gonzalez NS, Huss M, Saucier G, McGue M, MacMurray J (2000) Association between the adrenergic alpha $2 \mathrm{~A}$ receptor gene (ADRA2A) and measures of irritability, hostility, impulsivity and memory in normal subjects. Psychiatr Genet 10:39-42

Feng J, Zheng J, Gelernter J, Kranzler H, Cook E, Goldman D, Jones IR, Craddock N, Heston LL, Delisi L, Peltonen L, Bennett WP, Sommer SS (2001) An in-frame deletion in the alpha(2C) adrenergic receptor is common in African-Americans. Mol Psychiatry 6:168-172

Gabriel SB, Schaffner SF, Nguyen H, Moore JM, Roy J, Blumenstiel B, Higgins J, DeFelice M, Lochner A, Faggart M, Liu-Cordero SN, Rotimi C, Adeyemo A, Cooper R, Ward R, Lander ES, Daly MJ, Altshuler D (2002) The structure of haplotype blocks in the human genome. Science 296:2225-2229

Gavras I, Manolis AJ, Gavras H (2001) The alpha2 -adrenergic receptors in hypertension and heart failure: experimental and clinical studies. J Hypertens 19:2115-2124

Hein L (2001) [The alpha 2-adrenergic receptors: molecular structure and in vivo function]. Z Kardiol 90:607-612

Johansson C, Jansson M, Linner L, Yuan QP, Pedersen NL, Blackwood D, Barden N, Kelsoe J, Schalling M (2001) Genetics of affective disorders. Eur Neuropsychopharmacol 11:385-394

Kable JW, Murrin LC, Bylund DB (2000) In vivo gene modification elucidates subtype-specific functions of alpha(2)-adrenergic receptors. J Pharmacol Exp Ther 293:1-7 
Ke X, Cardon LR (2003) Efficient selective screening of haplotype tag SNPs. Bioinformatics 19:287-288

Kintsurashvili E, Johns C, Ignjacev I, Gavras I, Gavras H (2003) Central alpha2B-adrenergic receptor antisense in plasmid vector prolongs reversal of salt-dependent hypertension. J Hypertens 21:961-967

Lariviere WR, Wilson SG, Laughlin TM, Kokayeff A, West EE, Adhikari SM, Wan Y, Mogil JS (2002) Heritability of nociception. III. Genetic relationships among commonly used assays of nociception and hypersensitivity. Pain 97:75-86

Long JC, Williams RC, Urbanek M (1995) An E-M algorithm and testing strategy for multiple-locus haplotypes. Am J Hum Genet 56:799-810

MacDonald E, Kobilka BK, Scheinin M (1997) Gene targeting-homing in on alpha 2-adrenoceptor-subtype function. Trends Pharmacol Sci 18:211-219

Makaritsis KP, Handy DE, Johns C, Kobilka B, Gavras I, Gavras $\mathrm{H}$ (1999) Role of the alpha2B-adrenergic receptor in the development of salt-induced hypertension. Hypertension 33:1417

Mathias RA, Roy-Gagnon MH, Justice CM, Papanicolaou GJ, Fan YT, Pugh EW, Wilson AF (2003) Comparison of year-ofexam- and age-matched estimates of heritability in the Framingham Heart Study data. BMC Genet 4(Suppl 1): S36

McGrath JC, Brown CM, Wilson VG (1989) Alpha-adrenoceptors: a critical review. Med Res Rev 9:407-533

Shi MM, Myrand SP, Bleavins MR, de la Iglesia FA (1999) High throughput genotyping for the detection of a single nucleotide polymorphism in NAD(P)H quinone oxidoreductase (DT diaphorase) using TaqMan probes. Mol Pathol 52:295-299

Shishkina GT, Dygalo NN (2002) [Subtype-specific clinically important effects of alpha 2-adrenergic receptors]. Usp Fiziol Nauk 33:30-40

Sivenius K, Lindi V, Niskanen L, Laakso M, Uusitupa M (2001) Effect of a three-amino acid deletion in the alpha2B-adrenergic receptor gene on long-term body weight change in Finnish nondiabetic and type 2 diabetic subjects. Int $\mathbf{J}$ Obes Relat Metab Disord 25:1609-1614

Sivenius K, Niskanen L, Laakso M, Uusitupa M (2003) A deletion in the alpha2B-adrenergic receptor gene and autonomic nervous function in central obesity. Obes Res 11:962-970

Small KM, Liggett SB (2001) Identification and functional characterization of alpha(2)-adrenoceptor polymorphisms. Trends Pharmacol Sci 22:471-477

Small KM, Forbes SL, Brown KM, Liggett SB (2000a) An asn to lys polymorphism in the third intracellular loop of the human alpha 2A-adrenergic receptor imparts enhanced agonist-promoted Gi coupling. J Biol Chem 275:38518-38523

Small KM, Forbes SL, Rahman FF, Bridges KM, Liggett SB (2000b) A four amino acid deletion polymorphism in the third intracellular loop of the human alpha $2 \mathrm{C}$-adrenergic receptor confers impaired coupling to multiple effectors. J Biol Chem 275:23059-23064

Small KM, Brown KM, Forbes SL, Liggett SB (2001) Polymorphic deletion of three intracellular acidic residues of the alpha 2Badrenergic receptor decreases $\mathrm{G}$ protein-coupled receptor $\mathrm{ki}$ nase-mediated phosphorylation and desensitization. J Biol Chem 276:4917-4922

Stephens M, Smith NJ, Donnelly P (2001) A new statistical method for haplotype reconstruction from population data. Am J Hum Genet 68: 978-989

Timmermans PB, van Zwieten PA (1981) Mini-review. The postsynaptic alpha 2-adrenoreceptor. J Auton Pharmacol 1:171-183

Wall JD, Pritchard JK (2003a) Assessing the performance of the haplotype block model of linkage disequilibrium. Am J Hum Genet 73:502-515

Wall JD, Pritchard JK (2003b) Haplotype blocks and linkage disequilibrium in the human genome. Nat Rev Genet 4:587-597 